\title{
ANALISIS APLIKASI KEPEGAWAIAN PADA SISTEM INFORMASI MANAJEMEN KEJAKSAAN REPUBLIK INDONESIA (SIMKARI) DI KEJAKSAAN NEGERI BALE BANDUNG
}

\author{
Rosmalina \\ Program Studi Sistem Informasi Fakultas Teknologi Informasi \\ Universitas Bale Bandung \\ Rosmalina82@yahoo.com
}

\begin{abstract}
The Attorney as one of the law enforcement agencies is required to play a greater role in enforcing the law, protecting the public interest, upholding human rights, and eradicating corruption, collusion and nepotism. The use of management information and the software development at the State Attorney's office Bale Bandung (KEJARI) are a system to facilitate workers in managing and producing information easier. To input and save the data, an application called SIMKARI is needed which can support and help employees doing their work better and more effectively. This research was conducted by analyzing a personnel management information system (SIMPEG) which is part of the Republic of Indonesian Attorney's Management Information System (SIMKARI), this system is a helping aid to manage, record and enter data / information related to the personnel administration at the Republic of Indonesia Attorney's. The Features in the system are Data Rejuvenation, Employee History Entry, Employee Biodata, Control, Civil Servants and Employment Info. The analytical method used in this study is the PIECES method (Performance, Information, Economy, Control, Efficiency, and services). During the process of ongoing analysis the researcher did not conduct analysis based on the analysis methodology, but the researcher carried out the process of interviewing, observing and studying literature as a method of data collection
\end{abstract}

Keywords: SIM, PIECES, UML, SIMKARI, SIMPEG

ABSTRAK : Kejaksaan sebagai salah satu lembaga penegak hukum dituntut untuk lebih berperan dalam menegakkan hukum, perlindungan kepentingan umum, penegakkan hak asasi manusia, serta pemberantasan korupsi, kolusi, dan nepotisme. Penggunaan sistem informasi manajemen di KEJARI Bale Bandung serta pengembangkan perangkat lunak merupakan sebuah sistem untuk mempermudah pekerja dalam mengelola dan menghasilkan informasi. Untuk menginput dan meyimpan data tersebut dibutuhkan sebuah aplikasi yang dinamakan SIMKARI yang dapat mendukung untuk membantu pegawai dalam mengerjakan pekerjaan yang lebih baik dan efektif. Penelitian ini dilakukan dengan menganalisa sebuah sistem informasi Manajemen Kepegawaian (SIMPEG) yang merupakan bagian dari Sistem Informasi Manajemen Kejaksaan Republik Indonesia (SIMKARI), sistem ini merupakan sebuah alat bantu dalam mengelola, merekam dan meng-entry data/informasi terkait administrasi kepegawaian di Kejaksaan Republik Indonesia. Fitur yang ada dalam sitem tersebut antara lain Peremajaan Data, Entry Riwayat pegawai, menampilkan Biodata Pegawai, Pengendalian, Pengankatan PNS dan Info Kepegawaian. Metode analisis yang digunakan dalam penelitian ini adalah metode PIECES (Performance, Information, Economy, Control, Effisienci, dan services). Selama proses analisis berlangsung penulis tidak melakukan analisis berdasarkan metodologi analisis, namun penulis melakukan proses interview, observasi dan studi pustaka sebagai metode pengumpulan data.

Kata kunci: $\quad$ SIM, PIECES, UML, SIMKARI, SIMPEG

\section{PENDAHULUAN}

Sistem Informasi Manajemen Kejaksaan Republik Indonesia (SIMKARI) adalah aplikasi dan/atau alat bantu dalam pengelolaan administrasi secara komputerisasi yang terintegrasi ke seluruh unit kerja di Kejaksaan Agung, Kejaksaan Tinggi dan Kejaksaan Negeri seluruh Indonesia. SIMKARI tentunya menjadi solusi dari semua permasalahan administrasi, bertujuan untuk mengelola seluruh data dan Informasi Kejaksaan Republik Indonesia yang setiap saat dapat disajikan secara cepat, lengkap dan akurat.

Pengelolaan administrasi pegawai yang rapi dan terstruktur merupakan satu diantara beberapa aspek 
penting dalam manajemen sumber daya yang baik. Dengan adanya SIMKARI diharapkan menjadi solusi juga dalam pengelolaan administrasi pegawaisecara efektif dan efisien.

Sistem Informasi Manajemen Kepegawaian (SIMPEG) atau Aplikasi Kepegawaian adalah salah satu aplikasi yang terdapat dalam SIMKARI, berfungsi untuk mengelola, merekam dan menginput data/informasi terkait administrasi kepegawaian di Kejaksaan Republik Indonesia.

Adapun tujuan dilaksanakannya penelitian di KEJARI Bale Bandung adalah :

1. Menganalisa efektifitas dan efisiensinya SIMPEG pada SIMKARI ini dalam proses administrasi data karyawan di Kejaksaan Negeri Bale Bandung.

2. Menganalisa terintegrasinya SIMPEG ini dengan sistem lainnya di Kejaksaan Negeri Bale Bandung.

3. Memodelkan dan meng-capture sistem yang sedang berjalan baik secara garis besar sistem maupun secara mendetail

\section{LANDASAN TEORI}

\section{Analisis}

Menurut Dwi Prastowo Darminto Analisis merupakan penguraian suatu pokok atas berbagai bagiannya dan penelaahan bagian itu sendiri, serta hubungan antar bagian untuk memperoleh pengertian yang tepat dan pemahaman arti keseluruhan

\section{Sistem}

Menurut Malabay (2008, p305), sistem berasal dari bahasa Yunani yaitu "systema" yang mempunyai arti serangkaian dari objek-objek yang digabungkan oleh suatu kerangka interaksi atau saling bergantungan.

Sistem adalah kumpulan dari elemen-elemen yang saling berinteraksi untuk mencapai suatu tujuan tertentu; Sistem adalah jaringan kerja dari prosedurprosedur yang saling berhubungan, berkumpul bersama-sama untuk melakukan suatu kegiatan atau untuk menyelesaikan suatu sasaran tertentu.

\section{Informasi}

Menurut (McLeod, 2014), Informasi adalah data yang diolah menjadi bentuk lebih berguna dan lebih berarti bagi yang menerimanya.Informasi disebut juga data yang memiliki arti.Informasi merupakan data yang telah diproses sedemikian rupa sehingga meningkatkan pengetahuan seseorang yang menggunakannya.

\section{SIM}

Sistem Informasi Manajemen (SIM) adalah suatu metode formal untuk menyediakan informasi yang akurat dan tepat waktu bagi manajemen, yang diperlukan untuk mempermudah proses pengambilan keputusan dan memungkinkan fungsi-fungsi perencanaan, pengendalian dan operasional organisasi yang bersangkutan dapat dilakukan secara efektif. (Stone JAF, 1991).

\section{Metode PIECES}

- Analisis kinerja (Performance) adalah analisis terhadap kinerja yang diberikan oleh sistem informasi terkait dengan output yang diberikan

- Analisis informasi (information) adalah memberikan Informasi yang berkualitas yaitu informasi yang akurat, efisien dan tepat waktu

- Analisis ekonomi (economy) adalah Analisis ekonomi senantiasa berhubungan dengan keberadaan anggaran atau biaya perusahaan, analisis ekonomi bersifat mempelajari dan menerapkan tentang biaya dan manfaatnya

- Analisis pengendalian (control) adalah peningkatan terhadap pengendalian untuk mendeteksi dan memperbaiki kesalahankesalahan serta kekurangan-kekurangan yang akan terjadi. Pengendalian dalam sistem sangat diperlukan keberadaannya untuk menghindari dan mendeteksi secara dalam penyalahgunaan atau kesalahan sistem serta menjamin keamanan data dan informasi. Dengan adanya kontrol maka semua kinerja yang mengalami gangguan bisa cepat diperbaiki.

- Analisis Efisiensi (efficiency) ini erat hubungannya dengan input yaitu bagaimana sumber daya yang ada dapat digunakan seminimal mungkin sehingga tidak terjadi pemborosan. Tidak dapat

\section{METODE}

Metodologi analisis yang digunakan dalam penelitian ini adalah metode analisis PIECES (Performance, Information, Economy, Control, Effisienci, dan services)

\section{PEMBAHASAN}

\section{Analisis Aplikasi SIMKARI}

Sistem Informasi Manajemen Kejaksaan Republik Indonesia (SIMKARI) adalah aplikasi dan/atau alat bantu dalam pengelolaan administrasi secara komputerisasi dan terintegrasi ke seluruh unit kerja di Kejaksaan Agung (KEJAGUNG), Kejaksaan Tinggi (KEJATI) dan Kejaksaan Negeri (KEJARI) seluruh Indonesia. Pembangunan aplikasi ini dimaksudkan agar Kejaksaan RI memiliki basis data terkait semua kegiatan baik di KEJAGUNG, KEJATI dan KEJARI, serta tersedianya data warehouse berupa informasi yang relevan untuk kebutuhan mendukung 
pengambilan keputusan, dengan demikian maka Pimpinan dapat dengan mudah menjalankan fungsi monitoring, evaluasi dan pengendalian secara cepat dan transparan.

Aplikasi SIMKARI dibagi menjadi dua kategori, yaitu:

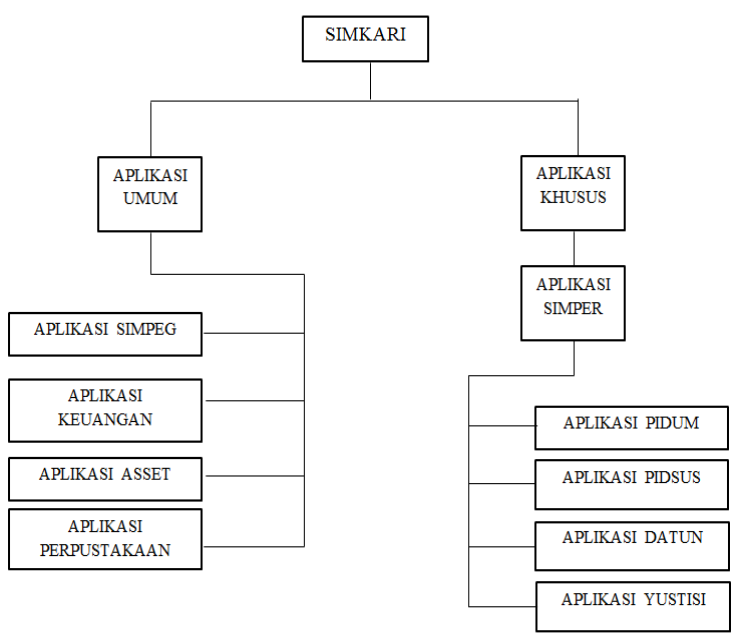

Gambar 1 kategori aplikasi SIMKARI

\section{Analisis Aplikasi Kepegawaian/ SIMPEG}

Sistem Informasi Manajemen Kepegawaian (SIMPEG) atau Aplikasi Kepegawaian berfungsi untuk mengelola, merekam dan meng-Entry data/informasi terkait administrasi kepegawaian di Kejaksaan Republik Indonesia. Namun, Aplikasi Kepegawaian pada aplikasi SIMKARI yang ada di KEJARI BALE BANDUNG ini hanya mampu/dapat meremajakan data, menampilkan data, report dan mencetak data saja, tidak dapat atau tidak ada hak untuk mengisi data (data pegawai/table master). Itu disebabkan karena Aplikasi ini merupakan aplikasi terpusat ke DASKRIMTI KEJAGUNG RI, yang berhak untuk mengisi/Entry data kepegawaiannya hanya Biro Kepegawaian Pusat, karena data pegawai yang diolah adalah data Pegawai Negeri.

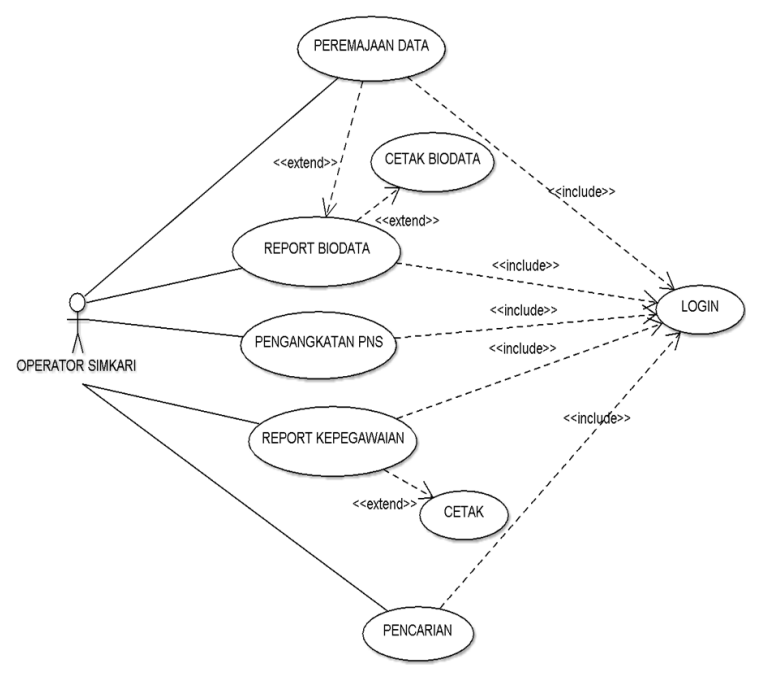

Gambar 2 use case diagram SIMPEG

3. Tampilan Aplikasi SIMKARI

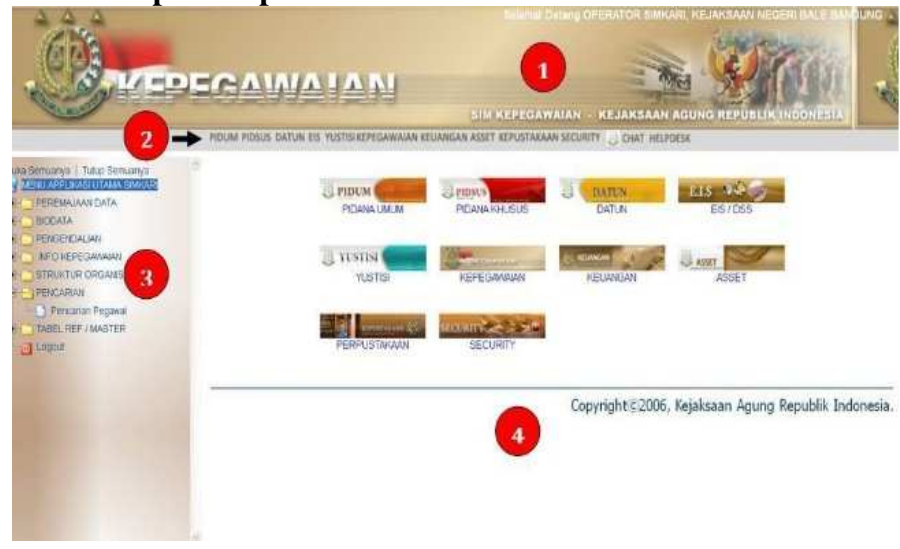

Gambar 3 tampilan umum SIMKARI

\section{Tampilan Aplikasi Kepegawaian}

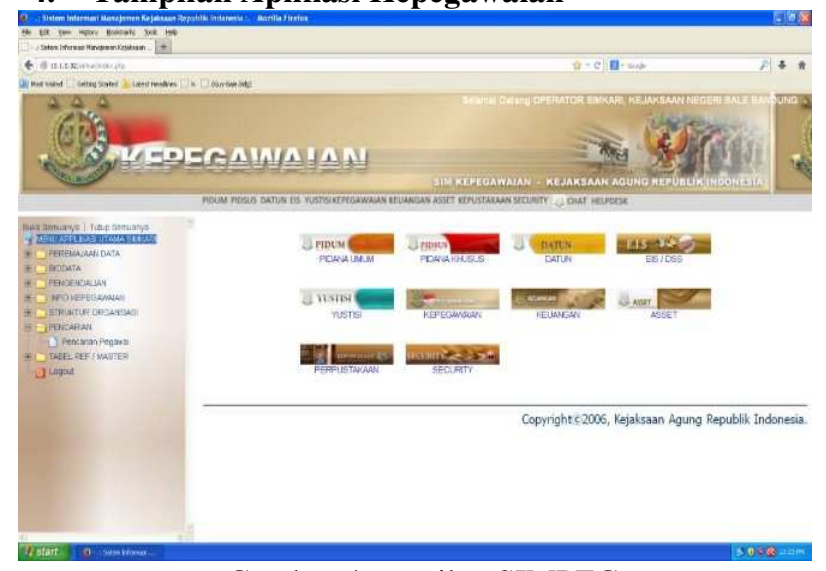

Gambar 4 tampilan SIMPEG 


\section{PEREMAJAAN DATA}

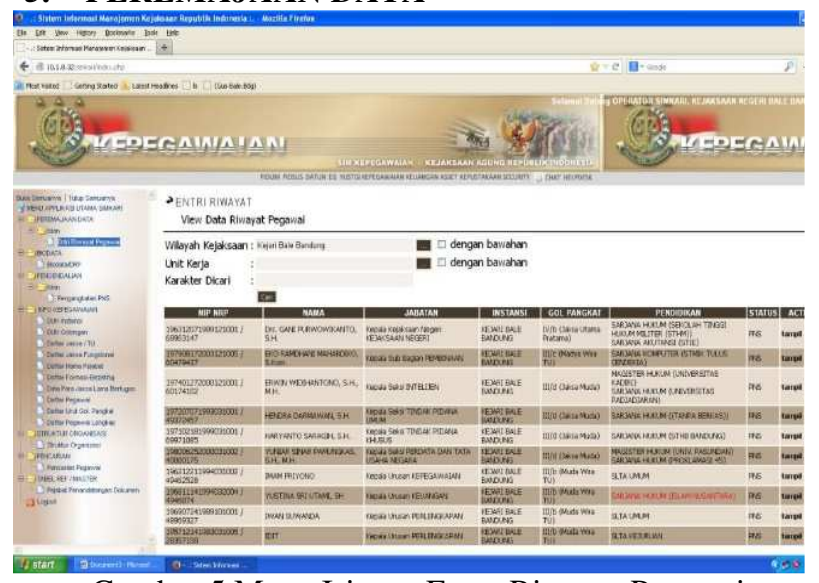

Gambar 5 Menu Isian -- Entry Riwayat Pegawai

6. Tmpilan data riwayat pegawai

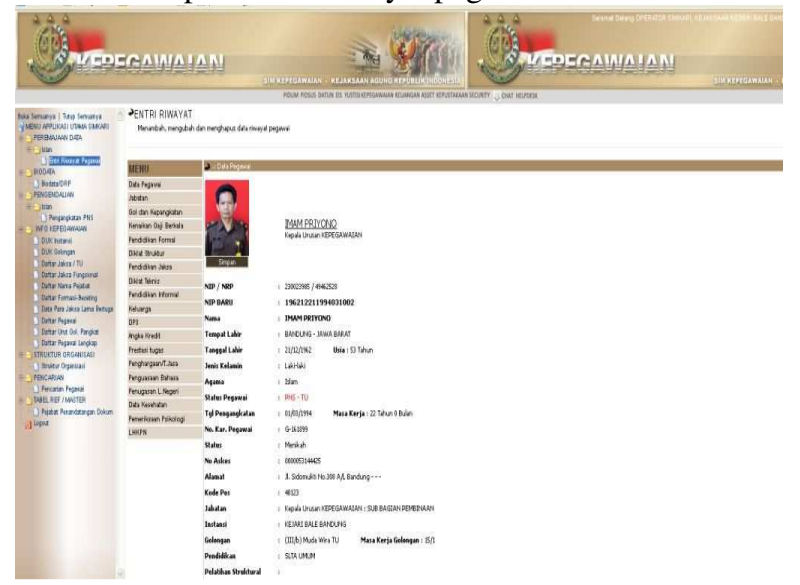

Gambar 6 tampilan riwayat pegawai

\section{Mengubah/Update Data Riwayat Pegawai} View Data Riwayat Pejawai

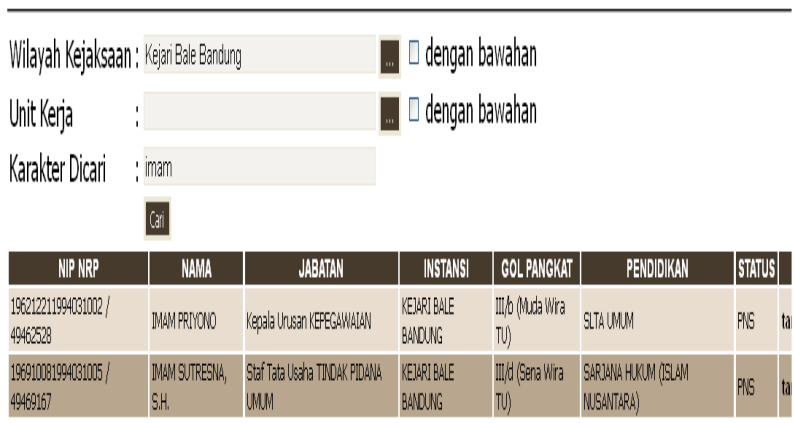

Gambar 7 tampilan update data riwayat pegawai
8. Tampilan biodata

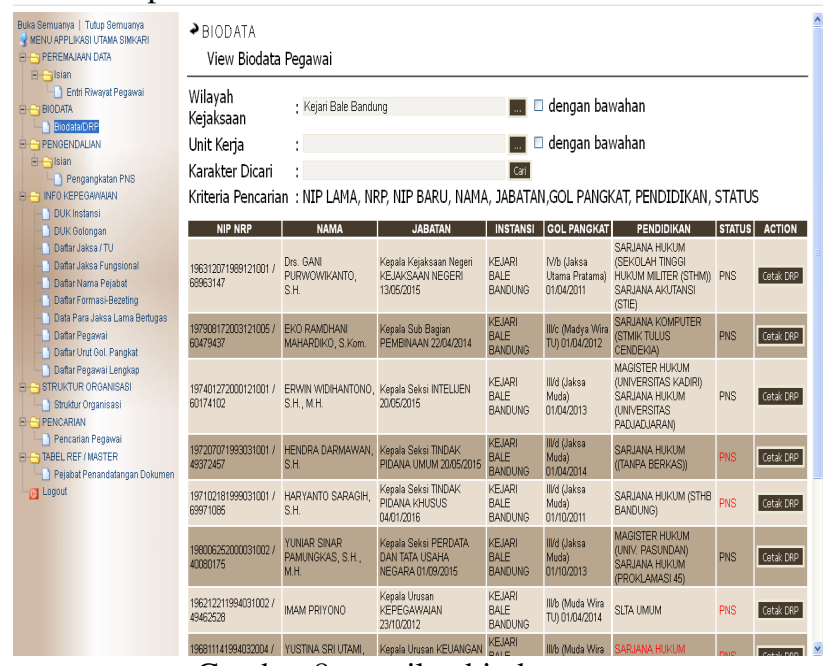

Gambar 8 tampilan biodata

9. Daftar urut golongan pangkat

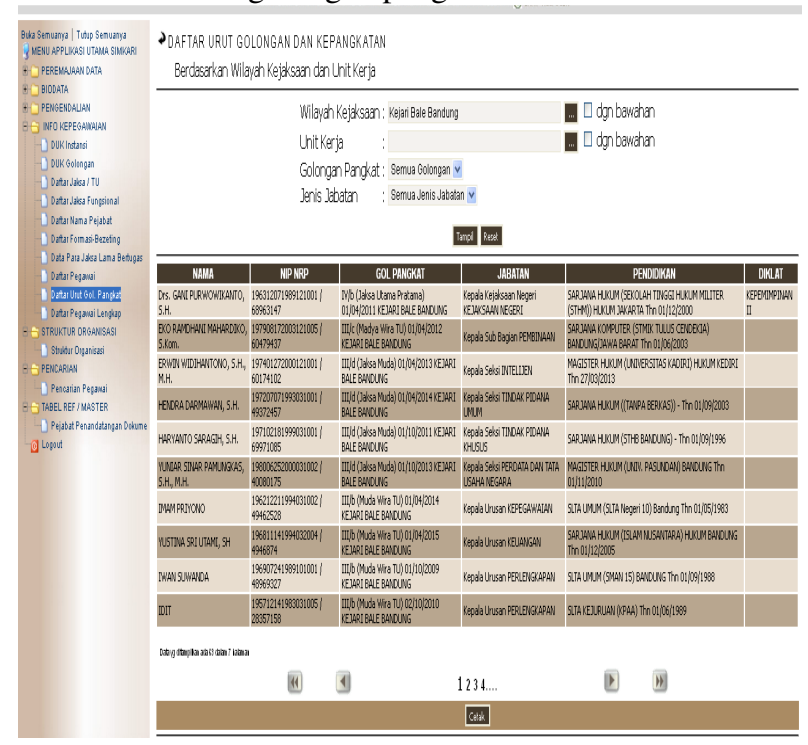

Gambar 9 tampilan daftar urut golongan pangkat
10. Analisis PIECES

- Analisis kinerja (performance)

Kinerja dari SIMPEG ini cukup baik, karena dari segi tampilan, pemilihan warna dan fitur- 
fitur didalamnya yang sederhana dan dapat dimengerti user. Proses pemasukkan data mudah dilakukan serta output (laporan) yang dihasilkan sesuai dengan kebutuhan user.

\section{- Analisis informasi (information)}

Pada SIMPEG ini informasi yang dihasilkan akurat karena informasi yang disampaikan sudah terstruktur sesuai dengan hak akses di masing-masing user sehingga menghasilkan informasi yang baik dan akurat serta meminimalisir kesalahan

\section{- Analisis ekonomi (economy)}

Analisis ekonomi senantiasa berhubungan dengan keberadaan anggaran atau biaya perusahaan, analisis ekonomi bersifat mempelajari dan menerapkan tentang biaya dan manfaatnya. Dengan adanya SIMPEG ini dapat bermanfaat dalam meminimalkan biaya yang dikeluarkan. Dengan adanya integrasi antar user dari sistem ini dapat menghemat waktu dan biaya dalam pengambilan dan pengiriman data yang berada di seluruh department.

- Analisis pengendalian (control)

Dengan adanya SIMPEG ini, kontrol terhadap informasi lebih mudah karena hak akses pada setiap user akan berbeda-beda tergantung pada tugas dan kewajiban di departemen masingmasing dan untuk keamanan dari masingmasing user pun akan terjaga dengan baik

- Analisis Efisiensi (efficiency)

Pada SIMPEG ini telah memiliki efisiensi yang baik, karena sistem yang ada telah dapat digunakan dengan baik dan juga dapat menghasilkan output yang diharapkan sesuai dengan kebutuhan user dan juga perusahaan.

- Analisis Layanan (Service)

Pelayanan pada SIMPEG ini diperlukan untuk meningkatkan kualitas dan kuantitas serta kepuasan pada masyarakat, karyawan maupun pimpinan di perusahaan.

\section{Evaluasi SIMPEG}

\section{Kemampuan dan Kelebihan Sistem}

- SIMKARI alat bantu dalam pengelolaan administrasi secara komputerisasi dan terintegrasi ke seluruh unit kerja di Kejaksaan Republik Indonesia.

- Sesuai dengan tujuan dibangunnya sistem yaitu Membantu dan memudahkan kinerja bagi Organisasi.

- Sistem ini Menjadi bahan remonerasi (nilai) atau tunjangan kinerja bagi instansi. Aplikasi/software ini didokumentasi dengan baik.

\section{Kekurangan/Kelemahan Sistem}

- Tidak adanya dialog berupa massage/pesan dalam sistem yang akan memudahkanUser untuk lebih mengerti/paham cara pengoperasian sistem.

- Sistem ini merupakan sistem yang besarnamun User hanya operator simkari. Sehingga User seringkali keteteran saat bekerja.

- Masih ada aktifitas dan alat bantu sistem yang tidak diperlukan, yaitu:

a) Mendownload terlebih dahulu data yang hendak dicetak;

b) Kolom Action Hapus; karena tidak ada kegiatan menghapus data.

- Masih ada keamanan dan pengendalian kesalahan yang kurang, contoh:

a) Data inputan masih bisa tersimpan walaupun belum lengkap.

b) Jaksa yang sudah tidak ada (pensiun atau meninggal) namun kasus perkara yang ditanganinya masih ada/belum selesai, maka data DPU tidak dapat diisi.

c) Data DPU yang tidak dapat diisi karena Jaksa yang sudah tidak ada masih bisa diisi manual atau diakali. (oleh tangan-tangan nakal)

- Aplikasi yang merupakan aplikasi terpusat ini memiliki kendala:

a) Karena yang meng-update data pegawai adalah pihak pusat/KEJAGUNG, dan pihak KEJATI atau KEJARI tidak berhak meng-update. Jika ada Pegawai yang meninggal, tapi datanya masih terdapat dalam sistem (database) sebagai pegawai satuan kerja KEJATI atau KEJARI. Maka pihak KEJATI atau KEJARI terlebih dahulu harus memberitahukan ke pihak pusat. Dan itupun masih dengan proses manual, yaitu dengan mengirim surat keterangan (misal surat keterangan meninggal).

b) Bila pegawai dimutasi oleh KEJAGUNG tapi DP3 dan Gaji Berkalanya belum masuk maka akan terjadi masalah atau kendala

\section{PENUTUP}

1. Kesimpulan

Pada umumnya Aplikasi Kepegawaian pada SIMKARI yang merupakan alat bantu dalam proses administrasi data karyawan di KEJARI Bale Bandung ini telah berfungsi dan berjalan dengan baikdan sudah cukup efektif dan efisien. 
- Aplikasi Kepegawaian atau SIMPEG ini terintegrasi atau saling berkaitan dengan sistem lainnya yang ada pada SIMKARI.

- Hasil dari penelitian adalah pemodelan sistem yang sedang berjalan dengan Metode Pendekatan Sistem Berbasis Objek yang menggunakan UML sertameng-capture sistem.

2. Saran

- Perlu adanya messege box pada saat setelah melakukan kegiatan menambahkan data, atau menghapus data agar memudahkan User untuk pengoperasian sistem.

- Akan lebih baik jika User bukanhanya operator SIMKARI, melainkan masing-masing Divisi dapat mengoperasikan sistem di bidang atau divisi mereka, karena akan lebih efektif jika sistem ini dioperasikan oleh bidangnya masingmasing, contoh SIMPEG oleh Bag. Kepegawaian atau Pembinaan. Tapi demi keamanan sistem harus dibatasi dalam hak akses User untuk dapat masuk dalam sistem, yakni dengan adanya akun dan password, sehingga User hanya dapat mengoperasikan sistem dalam bidangnya saja.

- Tidak perlunya mendownload data atau file yang akan dicetak, cukup langsung mencetakya secara online dari data pusat saja.

- Tidak perlunya Kolom Action Hapus karena tidak ada kegiatan menghapus data dalam sistem.

- Perlu adanya fasilitas back-up dan restore demi keamanan sistem.

\section{DAFTAR PUSTAKA}

[1] 2009. Manual Pengguna Aplikasi SIMKARI Modul Kepegawaian. Jakarta: Pusat Data Statistik Kriminal dan Teknologi Informasi.

[2] Hakim, Amir, dkk. 2013. Buku petunjuk pengelolaan SIMKARI. Jakarta: Pusat Data Statistik Kriminal dan Teknologi Informasi.

[3] Sugiarti, Yuni. 2013. Analisis dan Perancangan UML (Unifle Modeling Language) Generated VB.6.Yogyakarta: Graha Ilmu.

[4] Vidia Asri, Devit. 2013. Laporan Kerja Praktek: Analisis dan Perancangan Sistem Informasi Manajemen Bidang Teknologi Informasi Berbasis Web pada Subbid Tekinfo di Polda Jabar. Bandung.
[5] Yakub. 2012. Pengantar Sistem Informasi. Yogyakarta: Graha Ilmu.

[6] Yunara, Rani, dkk. 2012. Laporan Praktek Kerja Industri di Kejaksaan Negeri Bale Bandung. Bandung. 